\title{
TRADUÇÃO \\ Algumas considerações sobre a Filosofia da história de Kant $^{1}$
}

\author{
Ernst Cassirer ${ }^{2}$
}

\section{§ 1. Considerações metodológicas}

Ao lidar com o problema da história e do conhecimento histórico, Kant não pode proceder da mesma forma ou usar o mesmo método que usou em sua investigação crítica do conceito de natureza. „Natur” - diz Kant - „ist das Dasein der Dinge so fern es nach allgemeinen Gesetzen bestimmt ist" (Proleg[omena] § 14 - a natureza é a existência das coisas, na medida em que elas são determinadas segundo leis gerais). ${ }^{3}$ Se analisamos essas leis gerais, ${ }^{4}$ descobrimos que elas não são leis metafísicas ou ontológicas ${ }^{5}$ - mas leis lógicas. Elas não dependem da essência ${ }^{6} \mathrm{e}$ das qualidades das coisas em si mesmas, mas da natureza de nossa sensibilidade e de nosso entendimento. É a forma da nossa sensibilidade e de nosso entendimento que determina a forma geral da natureza. "Não importa quão exagerado e absurdo isso possa soar" - diz Kant em sua analítica transcendental (Edição A, p. 126f.) -

que o entendimento é ele mesmo a fonte das leis da natureza e de sua unidade formal, tal declaração é, entretanto, correta e está de acordo com a experiência. É bem verdade, sem dúvidas, que as leis empíricas enquanto tais não podem derivar

1 Tradução de Rafael Rodrigues Garcia (Universidade Estadual de Campinas). Nota do editor (N.E): O bloco de papéis está envolvido por uma folha com a inscrição no lado da frente: Filosofia da História/Kant; do lado de trás encontra-se um texto completamente riscado em inglês sobre a doutrina de Pavlov dos reflexos condicionados.

2 Cassirer ministra essa palestra no curso The Philosophy of History, que ele conduz no ano letivo de 1941/42 na Yale University com outros colegas. Ver 1941-[19]42 XXIX. Philosophy ... Yale University Graduate School. Description of Courses. Graduate Courses: Philosophy 121, The Philosophy of History. Mr. Cassirer, Mr. Hendel, Mr. Holborn. The philosophy of history and the significance of history for philosophy. Wed. 4-6, p. 182; ver também Editorische Hinweise in ECN 16, pp. 220-224. [N.E]

3 Ver Kant, I. „Prolegomena zu einer jeden künftigen Metaphysik“. In: Werke. In: Gemeinschaft mit Hermann Cohen, Artur Buchenau, Otto Buek, Albert Görland, B[enzion] Kellermann ed. Ernst Cassirer. 10 Bde. Berlim 1912-1922. (= Werke) Bd. 4: Schriften von 1783-1788. Ed. Artur Vuchenau e Ernst Cassirer. Berlim, 1913, §14, p. 44; Inglês: Kant, I. "Prolegomena to any future Metaphysic". In: Kant's Critical Philosophy for English Readers. By John P. Mahaffy and John H. Bernard. New York 1889. Vol. 1, § 14, p. 49. [N.E.]. Em português, vale citar a tradução feita por Artur Morão: Prolegômenos a toda metafísica futura que queira apresentar-se como ciência. Lisboa: Edições 70, 1988. [Nota do tradutor (N.T)]

4 Sobre a linha riscado: regras [rules].

5 A seguir riscado: regras - regras que consideram e determinam a essência das coisas elas mesmas.

6 Riscado sobre a linha: natureza. 
sua origem do entendimento puro, tampouco quanto a multiplicidade infinita dos fenômenos poderia ser suficientemente compreendida através da forma pura da intuição sensível. Mas todas as leis empíricas são só determinações particulares das leis puras do entendimento (...) O entendimento não é somente uma faculdade de fazer leis por uma comparação de fenômenos, ele é o próprio o legislador da natureza, e sem o entendimento a natureza, que é a unidade sintética dos fenômenos de acordo com regras, não seria encontrada em lugar algum porque os fenômenos, como tais, não podem existir sem nós, mas sim existem somente em nossa sensibilidade. ${ }^{7}$

Mas o idealismo de Kant adquire uma configuração perfeitamente nova quando Kant passa do mundo da natureza para o mundo da história. Aqui temos de encarar o dualismo fundamental que está no cerne de todo o sistema kantiano. A história não pode ser interpretada do mesmo modo e não pode ser explicada de acordo com as mesmas regras gerais que a natureza. A natureza é a esfera da necessidade, a história é a esfera da liberdade. Essa esfera não pode ser descrita nos termos da mera causalidade empírica. Ela não é somente uma ordem empírica - uma ordem de eventos singulares no espaço e no tempo - mas uma ordem inteligível. Ela não depende da concatenação de meros fatos físicos e de forças físicas; depende de ações humanas, ou da vontade livre do homem. Mas aqui começa a real dificuldade. Podemos falar de leis da liberdade no mesmo sentido que falamos de leis da natureza? Podemos prever e predeterminar a ordem e o plano geral dos eventos históricos ou tal determinação não seria o exato oposto de nossa ideia de liberdade? Mesmo de um ponto de vista meramente epistemológico, não podemos ter expectativas de uma filosofia da história ${ }^{8}$ - no mesmo sentido em que falamos de uma filosofia da natureza. A natureza pertence ao mundo fenomênico, a história ao mundo numênico. A primeira se ocupa da conexão empírica de causas e efeitos, a última, com a conexão de meios e fins. A análise das categorias do entendimento puro é, portanto, incapaz de fornecer uma aproximação verdadeira e segura para a história. Aqui temos de escolher ${ }^{9}$ um caminho diferente; temos de começar com a análise geral de nossos juízos teleológicos. Uma inspeção sistemática desses juízos é a condição primeira e indispensável para o tratamento crítico dos problemas da história. ${ }^{10}$

7 Cf. Kant, I. Critique of Pure Reason. In Commemoration of the Centenary of its First Publication. Translated into English by F[riedrich] Max Müller. Second Part. London 1881, p.111f. (A 127f., A 126f.); Alemão: Kant, I. Kritik der reinen Vernunft. In: Werke. Bd. 3. Hrsg. von Albert Görland. Berlin 1913, S. 627 (A 127f., A 126f.). [N.E.]. É válido mencionar a tradução para português de Manuela Pinto dos Santos e Alexandre Fradique Morujão: Crítica da razão pura. Lisboa: Fundação Calouste Gulbenkian, 2001. [N.T]

$8 \mathrm{Em}$ vez do riscado: filosofia.

9 [choose] chose.

10 Meio do Ms. - p. 4, flecha curta para baixo: cont[inuação] v[er] p. 8; Ms. - pp. 5-6 faltantes no bloco, Ms. - p. 7 completamente riscada. 


\section{§ 2. A crítica da teleologia de Kant ${ }^{11}$}

1. É difícil, se não impossível, resumir numa fórmula breve a visão geral de Kant no que concerne à validade objetiva de nossos juízos teleológicos. Porque aqui, tal como em outros casos, Kant precisa pavimentar seu caminho. Ele não pode seguir a tradição metafísica geral e não pode aceitar os termos que foram introduzidos por essa tradição. Na filosofia dos séculos XVII e XVIII, o pensamento metafísico, com respeito ao problema da teleologia, é dividido em dois campos diferentes e opostos. Leibniz mantém e defende a posição clássica: a de Aristóteles. Nossos conceitos e juízos teleológicos não são de modo algum uma mera forma do pensamento humano. Eles expressam, ao contrário, a própria essência das coisas; eles penetram no cerne da realidade. De outro lado encontramos a filosofia de Espinosa, que nega toda verdade objetiva a nossos juízos teleológicos e rejeita firmemente todas aquelas formas de metafísica que são erigidas sobre juízos desse tipo. O conceito de "propósito" não inclui nenhuma verdade metafísica. Ele não é senão um "asylum ignorantiae" 12 uma fonte perpétua de erro e ilusão. Kant não aceita nem a declaração positiva de Leibniz nem a tese negativa de Espinosa. Ele pensa que ambas são dogmáticas e, portanto, assertivas infundadas. É somente após uma completa e cuidadosa análise crítica das diferentes formas de nossos juízos teleológicos que podemos chegar a um claro entendimento e a uma solução adequada para ${ }^{13}$ o nosso problema. Kant executou essa tarefa na terceira parte de sua Crítica da razão pura, na dialética transcendental, e em sua Crítica da faculdade de julgar. Na dialética transcendental, ele ataca o uso transcendente do conceito de propósito e intencionalidade [purpose and purposiveness]. ${ }^{14} \mathrm{~A}$ famosa "prova físico-teológica da existência de Deus" ${ }^{15}$ prova

11 Começo da Ms.- p. 8, no verso da qual se encontra uma Ms.-p.7 a lápis completamente riscada: "como uma ordem geral [riscada: necessária] e inevitável de causas e efeitos; a história pertence [riscado: a uma ordem distinta,] ao 'reino dos fins'. Esse [riscado: ordem] reino nunca pode ser descrito de um modo adequado em termos de mera causalidade. A natureza é a expressão da ordem empírica de eventos no espaço e no tempo - uma ordem que prova ser [riscado: por uma investigação crítica] uma ordem de 'meras aparências'. Mas a história depende das ações humanas - de ações que são levadas a cabo não pela natureza, mas pela vontade livre do homem. [riscado: Esse; Aqui encontramos a única possível entrada que imediatamente nos conduz] Quando na passagem do limiar da história nós somos, portanto, imediatamente levados para um novo mundo: a um [riscado: mundo de] 'mundo inteligível' [riscado: (mundus intelligibilis)], [riscado: no] um mundo de 'noumena', em vez de meros phenomena. A base desse mundo não é para ser buscada na conexão causal de eventos, mas numa conexão entre 'fins' e 'meios'. É esse o ponto no qual temos de concentrar todos os nossos esforços [riscado: empíricos] críticos, se não buscamos por encontrar uma fundação nova e mais segura para nossos juízos teleológicos - não podemos ter a esperança de atingir nosso fim, de chegar a uma filosofia crítica da história. Fim.".

12 (lat.) refúgio da ignorância. [N.E.]

13 de

14 Riscado em seguida: Ambas ruem tão logo tentemos provar por meio delas qualquer tese metafísica fundamental. Ela [folha completamente riscada] de todas, a.

15 Comparar com Kant, I. Critique of Pure Reason. (Müller) Second Part, Of the impossibility of the Physico-theological proof, pp. 532-541 (A 620-A 630); Alemão: Kant, I. Kritik der reinen Vernunft. 
ser uma mera falácia ${ }^{16}$ metafísica. Mas se não podemos usar a ideia de uma ordem teleológica das coisas como uma ponte que nos leva do mundo empírico para a sua causa transcendente, da natureza para Deus, permanece ainda assim a esperança de provar a validade objetiva de nossos conceitos teleológicos no campo da própria natureza. Na realidade, nós pensamos que aqui é uma esfera da natureza - a esfera da vida orgânica - que não pode nunca ${ }^{17}$ ser descrita, de modo adequado e exaustivo, em termos de mera causalidade. Para formar o conceito de um "organismo", temos sempre de recorrer a uma fonte diferente de conhecimento. Um organismo não pode ser explicado apenas em princípios mecânicos. Ele não é apenas um sistema de causas e efeitos. Por um produto organizado da natureza - diz Kant (Crítica da faculdade de julgar \$66) -entendemos um produto no qual tudo é reciprocamente fim e meio. Nada nele é vão ou sem propósito; nada pode ser atribuído a um mecanismo cego da natureza. ${ }^{18}$ Aqui, portanto, parece ${ }^{19}$ que averiguamos a validade objetiva completa de nossos juízos teleológicos. Mas mesmo aqui nós temos de entender a verdade desses juízos num sentido relativo, não num absoluto. Eles não concernem e não expressam a realidade última, a realidade das coisas em si mesmas - o que eles expressam é a forma necessária de nosso próprio entendimento ou, para colocar em termos do próprio Kant, de nossa faculdade de julgar. "Propósito" e "intencionalidade" são conceitos que não descrevem a natureza das coisas, mas nosso modo de conceber coisas. Eles não determinam a essência metafísica das coisas, mas regulam o curso de nossa razão em sua reflexão sobre a natureza. Todos os nossos juízos teleológicos são juízos reflexivos. A realidade "objetiva” do conceito de um propósito não pode ser estabelecida se essa "realidade objetiva" for entendida num sentido dogmático e metafísico. Mas ela pode muito bem e deve, com efeito, ser admitida se usamos o conceito num sentido metodológico, para mera reflexão. 0 conceito de um propósito não é apenas admissível, mas é inevitável, se nós restringirmos seu uso a essa condição - se nós não o entendermos como um conceito objetivamente determinante, que determinaria a natureza como tal e atribuiria a ela propósitos e intenções suas, mas pensamos nele apenas como um conceito reflexivo. A ideia de um propósito

In: Werke. Bd. 3, Von der Unmöglichkeit des physiko-theologischen Beweises, pp. 427-433 (B 631-B 658). [N.E.]

16 Em seguida à lápis, entre parênteses e riscado: "Em contradistinção a Espinosa, Kant admite que essa prova sempre merecerá ser tratada com respeito. Ela é, como ele diz, a mais antiga e clara, e a mais em conformidade com a razão humana. Ela dá vida ao estudo da natureza, derivando sua própria existência da razão, e assim constantemente requerendo novo vigor. Mas ainda assim a filosofia crítica não pode nunca aprovar a pretensão que essa prova tem de avançar a uma certeza apodítica. A respeito disso ela está aberta às mais sérias e irrespondíveis objeções".

17 Never can; corrigido a seguir tacitamente.

18 Comparar com Kant, I. Critique of Judgment. Translated with Instruction and Notes by J. H. Bernard. (1892) Second Edition revised. London 1914, § 66, p. 280f.; Alemão: Kant, I. Kritik der Urteilskraft. Hrsg. von Otto Buek. In: Werke. Bd. 5. Berlin 1914, § 66, p. 454. [N.E.]

19 [para] em seguida riscado: sobre um solo firme e inabalável; nós 
pode, portanto, ser usada por um juízo refletivo, mas somente por causa da própria reflexão. "Mas para representar a natureza a alguém tecnicamente como se ela fosse racional ('gleich einer Vernunft')" e então atribuir à natureza intencionalidade ou mesmo propósitos, - esse é um conceito específico que não pode ser encontrado na experiência"20 (Primeira introdução de Kant à Crítica da faculdade de julgar, Werke, Cassirer [vol.] V, [p.] 214 e ss.). Eu não posso esperar aqui elucidar o problema de uma "teleologia da natureza" - um problema que pertence às questões mais difíceis e mais avidamente debatidas de todo o sistema kantiano. Dentro do escopo de nossa própria tarefa, eu me contento com essas alusões breves e muito insuficientes.

\section{§3. A aplicação da Crítica da Teleologia de Kant ao problema de uma Filosofia da história}

Pensamos que Kant não apenas admite, mas que, em certo sentido, enfatiza fortemente a possibilidade de uma teleologia da natureza. Mas de outro lado ele nos alerta constantemente a respeito dos perigos que tal conceito contém se ele for entendido de um modo errôneo, acrítico ${ }^{21}$. A ciência da natureza não pode jamais se sentir perfeitamente satisfeita antes de ter alcançado a explicação para o fenômeno da natureza de acordo com os princípios de um mecanismo estrito. O conceito de "Naturzweck" sempre permanece em certo sentido um "Fremdling in der Naturwissenschaft"22 - um estranho e uma espécie de intruso no campo da ciência. De acordo com Kant, todos os sistemas filosóficos prévios - de Aristóteles a Leibniz - erraram o alvo porque procuraram a origem e a fonte da teleologia no lugar errado. Eles entenderam a teleologia ou num sentido metafísico ou num sentido físico. Mas a verdade da teleologia não se encontra na física ou na metafísica. Se falamos das finalidades de Deus ou das finalidades da natureza estamos usando esses termos em ambos os casos num sentido meramente metafórico. Pensamos em Deus como um humano artesão ou o mestre-de-obras que começa por legar um esquema geral das coisas e que, mais tarde, tem de pensar sobre o meio mais apropriado para atualizar esse plano geral. E o mesmo tipo de antropomorfismo nós encontramos em todas as doutrinas que concebem a natureza como um sistema teleológico, um

20 Cassirer não dá uma tradução da Primeira introdução para o inglês, provavelmente porque ele mesmo teria traduzido a passagem. Cf. Kant, I. First introduction to the Critique of the Power of Judgment. In: Critique of the power of judgement. Edited by Paul Guyer. Transladed by Eric Matthews. Cambridge 2000 pp. 1-52, p. 35f.; Alemão: Erste Einleitung in die Kritik der Urteilskraft. Hrsg. von Otto Buek. In: Werke. Bd. 5, p. 214f. [N.E.]. Em português, indicamos a tradução de Fernando Costa Mattos: Crítica da faculdade de julgar. Petrópolis: Vozes, 2016. Na passagem citada, p. 285. [N.T]

21 Em seguida riscado: quando lidando com o mundo da biologia, com a vida orgânica, nós devemos e temos de, com efeito, fazer uso de uma interpretação teleológica do fenômeno da natureza. Mas de outro lado nós temos de ser muito cautelosos em tal fim.

22 Cf. Kant, I. Kritik der Urteilskraft. In: Werke. Bd. 5, § 72, p. 468. [N.E.] 
sistema de meios e fins. Para descobrir o significado real dos termos "propósito" e "intencionalidade" e para usar esses termos em seu sentido verdadeiro e adequado, nós temos de mudar nosso ponto de vista; temos de nos aproximar do problema por um ângulo diferente. 0 problema não admite qualquer solução metafísica ou física; ele admite apenas uma solução ética. 0 único acesso crítico possível à nossa questão deve ser encontrado na ética. Na ética, somente, situamo-nos, no que tange ao nosso problema, sobre um solo firme e inabalável. Não podemos jamais encontrar um fim real, absoluto, enquanto nos movermos na esfera dos objetos ${ }^{23}$ empíricos. É somente através da liberdade, não através da natureza, que podemos entrar no "reino dos fins". É apenas ao homem, como um ser livre, que podemos atribuir um fim absoluto e uma dignidade absoluta. Esse é o sentido ${ }^{24}$ fundamental do imperativo categórico de Kant ${ }^{25}$.

O homem e qualquer ser racional existe como um fim em si mesmo, não meramente como um meio a ser usado arbitrariamente por esta ou aquela vontade, mas sim, em todas as suas ações, quer sejam concernentes a si mesmo ou a outros seres racionais, deve ser sempre considerado ao mesmo tempo como um fim (...) se toda a dignidade fosse condicionada e, portanto, contingente, então não haveria qualquer princípio supremo prático da razão. Se há um princípio supremo prático ou, em respeito à vontade humana, um imperativo categórico, ele deve ser um que, sendo extraído da concepção daquilo que é necessariamente um fim para todos porque é um fim em si mesmo, constitui um princípio objetivo da vontade e pode, portanto, servir como uma lei prática. A fundação desse princípio é "a natureza racional existe como um fim em si mesma ${ }^{26}$ (Kant, I. Grundlegung zur Metaphysik der Sitten. In: Werke (Cassirer) [Bd.] IV, [S.] 286f). ${ }^{27}$

Em sua concepção ética fundamental está implícita toda a filosofia da história de Kant. O que distingue a filosofia kantiana da história até mesmo daqueles pensadores que pretenderam seguir o caminho de $\mathrm{Kant}^{28}$ é o fato de que a base do sistema kantiano não é especulativa, mas mera e exclusivamente ética. Hegel definiu a história como o progresso na consciência da liberdade. Essa definição está em acordo estrito com Kant, e é emprestada dos próprios termos de Kant. Mas o sentido de "liberdade" não é o mesmo nos sistemas kantiano e hegeliano. Pois em Kant a liberdade não significa um princípio teórico especulativo; ela significa uma

23 Em seguida riscado: de fins físicos

24 Riscado na margem direita, em vez de: princípio.

25 Em seguida riscado: Ética - o sentido ultimo de seu.

26 Em seguida riscada a citação seguinte: De acordo, o imperativo prático será como se segue: "Aja de modo a tratar a humanidade, seja em sua própria pessoa ou em qualquer outra, em todo caso ao mesmo tempo como um [no manuscrito: e] fim, nunca somente como um meio".

27 Cf. Kant, I. "Fundamental Principles of the Metaphysic of Morals". In: Critique of Practical Reason and Other Works on The Theory of Ethics. Translated by Thomas Kingsmill Abbott. 5th Edition. London / New York / Bombay 1898, p. 47; Alemão: Kant, I. Grundlegung zur Metaphysik der Sitten. In: Werke. Bd. 4: Schriften von 1783-1788. Hrsg. von Artur Buchenau und Ernst Cassirer. Berlin 1913, p.287. [N.E.]

28 Em seguida riscado: - especialmente de Hegel 
ideia, um postulado da nossa razão prática. A liberdade não é “gegeben”, mas sim é "aufgegeben"29; ela não é um datum empírico ou metafísico, ela é uma tarefa ética. Assim todo o problema de uma filosofia da história muda completamente sua feição. Nós não podemos ter esperanças de predizer o curso futuro dos eventos históricos. Não há um esquema lógico, nenhum esquema do pensamento dialético no qual nós possamos forçar os fatos históricos como num leito de Procusto ${ }^{30}$. Um filósofo da história não pode reivindicar ser um profeta. Nós não sabemos dos meios particulares pelos quais a humanidade alcançará seu fim moral. Mas, de outro lado, não podemos nunca duvidar ou perder as esperanças quanto à possibilidade de atingir este fim mais alto e último. Pois tal dúvida é proibida por um dos princípios fundamentais da filosofia moral de Kant - pelo princípio “Du kannst, denn Du sollst!"31 "tu deves, portanto tu podes". ${ }^{32}$ Esse princípio não pode ser provado ${ }^{33}$ de um modo especulativo - ao modo do método dialético hegeliano. Ele possui, entretanto, a mais alta certeza: a certeza não de um dogma teórico, mas de uma "Vernunftglauben"34, de uma crença ${ }^{35}$ racional prática. Toda a filosofia da história não pode ser outra coisa nem nada além do que tal crença ${ }^{36}$ prática - uma crença de que deve ser possível ao homem satisfazer sua destinação moral, erigir um reino da liberdade real.

Uma visão meramente empírica não poderia jamais dar conta de confirmar e provar essa concepção ${ }^{37}$. Pois a história empírica está em acentuado contraste com nossos postulados éticos, com nosso ideal de liberdade. 'L'homme est né libre< - diz Rousseau - set partout il est ${ }^{38}$ dans les fers ${ }^{39}$ < - "O homem nasce livre, e em toda parte está acorrentado". ${ }^{40}$ Essa é também a visão de Kant, que a esse respeito

29 As palavras atribuídas a Kant de algo (o próprio transcendental) que não nos é "dado", mas sim "proposto" [mais literalmente, posto como tarefa - Nota do tradutor], encontram-se p. ex. na Crítica da razão pura de um jeito modificado. Cf. Kant, I. Kritik der reinen Vernunft. In: Werke. Bd. 3, S. 353 (B 526). [N.E.]

30 Na margem superior do Manuscrito, p. 18, acrescentado sobre a primeira linha.

31 Essa citação frequentemente atribuída a Kant de modo falso provém de um poema de Schiller: „Auf theoretischem Feld ist weiter nichts mehr zu finden; Aber der praktische Satz gilt doch: Du kannst, denn du sollst!“ - Cf. Schiller, F. Die Philosophen. In: Sämtliche Werke. Bd. 1: Gedichte 1. Stuttgart / Berlin o.J., Anhang, S. 266-268, hier: p. 267. [N.E.]

32 Claramente traduzido pelo próprio Cassirer do alemão. Uma tradução moderna diz: thou canst, for thou shouldst! -- Cf. Schiller, F. "Philosophers". In: Delphi Classics Complete Works. [N.E.]

33 Em seguida riscado: - de [modo] empírico ou

34 Cf. Kant, I. Kritik der praktischen Vernunft. Hrsg. von Benzion Kellermann. In: Werke. Bd. 5. Berlin 1914, S. 158. [N.E.]

35 Riscado sobre a linha: fé [creed].

36 Riscado sobre a linha: fé [creed].

37 Sob a linha riscado: visão.

38 Sobre a linha riscado: nós o encontramos.

39 Cf. Rousseau, J-J. Du contrat social. In: Oeuvres complètes de J. J. Rousseau. Nouvelle Edition. Avec les notes historiques et critiques de tous les commentateurs. Paris 1832. Tome 5, Livre I, Chap. I: Sujet de ce primier livre, p. 26. [N.E.]

40 * + Sr. Hendel: Por favor corrija a citação! / Eu tive de citar de memória. Na margem superior do 
sente e pensa como um discípulo de Rousseau. Liberdade é o mais alto ideal e a tarefa última do homem, mas ela nunca é atualizada na história real. Todas as formas empíricas de vida social e política que até então surgiram na história não são baseadas na liberdade, mas na força física. Elas não são formas de libertação da humanidade; a maioria delas provaram ser meros meios de opressão, de despotismo e tirania. Mas essa consideração empírica não nos liberta de nosso dever moral que nos é prescrito pela nossa razão prática de modo claro e unívoco. Temos de mudar esse estado de coisas humanas; temos de transformar por nossa própria vontade, por um esforço moral consistente, a necessidade em liberdade. Quando olhamos para a história da humanidade, vemos que o homem até hoje nunca viveu ${ }^{41}$ num verdadeiro "Vernunftstaat", mas num mero "Notstaat" 42 (um termo não usado pelo próprio Kant, mas introduzido por Schiller em suas cartas sobre a educação estética da humanidade). Mas no futuro há de ser de outro modo, porque deve ser de outro modo. O homem cessará de ser uma mera ferramenta nas mãos do destino. Ele se tornará mestre de seu próprio mundo - do mundo da humanidade. É somente assim que ele pode provar sua liberdade prática, que não é senão sua autonomia ética. 0 homem - e somente o homem - possui "uma força que o eleva acima de si mesmo (como uma parte do mundo sensível). Essa força não é senão personalidade que é liberdade e independência do ${ }^{43}$ mecanismo da natureza; de modo que a pessoa, como pertencente ao mundo sensível, está sujeita à sua própria personalidade como pertencente ao mundo inteligível" 44 (Cf. [Kant]. Critique of practical reason. Ed[ited by] Cassirer, [Tomo] V, [p.] 95ss.)..$^{45}$ Toda a filosofia da história de Kant está contida nessa pressuposição e nessa demanda fundamental ${ }^{46}$. A filosofia da história de Kant não é uma parte autocontida, independente de seu sistema crítico; ela deve ser entendida e deve ser interpretada como um mero corolário de seu pensamento ético. O próprio Kant deu essa interpretação com uma clareza e consciência admiráveis em seu tratado "Idee zu einer allgemeinen Geschichte in weltbürgerlicher Absicht"47 (1784). “A história da raça humana vista como um todo pode ser tomada como a

manuscrito, p. 19.

41 Sobre a linha riscado: como não

42 Cf. Schiller, F.. Über die ästhetische Erziehung des Menschen in einer Reihe von Briefen In: Sämtliche Werke. Säkular-Ausgabe in 16 Bänden. Hrsg. von Eduard von der Hellen. Bd.12: Philosophische Schriften. Zweiter Teil. Stuttgart und Berlin 1905, 4. Brief, p. 12; siehe auch 3. und 13. Brief., SS. 7f., 52. [N.E.]

43 Riscado: do

44 Cf. Kant, I. "Critical Examination of Practical Reason”. In: Critique of Practical Reason and Other Works on The Theory of Ethics. (Abbott), p. 180; cf. Kant, I. Kritik der praktischen Vernunft. In: Werke. Bd. 5, S. 95f. [N.E.]

45 Em português, tradução de Monique Hulshof: Crítica da razão prática. Petrópolis: Vozes, 2016 [N.T].

46 Riscado em seguida: ético.

47 Ideia de uma história universal de um ponto de vista cosmopolita. [N.T]. 
realização de um plano secreto da Natureza para ocasionar uma constituição política, internamente, e para esse propósito também externamente perfeita, como o único estado no qual todas as capacidades implantadas por ela na humanidade podem ser completamente desenvolvidas".

Essa nova concepção de história provou ser extremamente fértil tanto para o pensamento filosófico geral quanto para o pensamento histórico empírico - nós podemos seguir esse desenvolvimento tanto na obra de Ranke quanto na de Hegel. ${ }^{48}$

Recebido em: 17.09.2017

Aceito em: 25.01.2018

48 Alusão à palestra Some Remarks on Hegel's Theory of the State [Algumas considerações sobre a teoria do Estado de Hegel - N.T.] que ele apresentou em fevereiro de 1942 no mesmo curso The Philosophy of History, ver reprodução em: ECN 16, S. 178-193. [N.E.] 